Article

\title{
Can cryptocurrencies be a safe haven during the novel COVID-19 pandemic? Evidence from the Tunisian Stock Market
}

\author{
Ahmed Jeribi ${ }^{*}$, and Yasmine Snene Manzli² \\ 1 Faculty of Economics and Management of Mahdia, Université de Monastir, Tunisia; ahmedjeribi07@yahoo.fr \\ 2 Faculty of Economics and Management of Mahdia, Université de Monastir, Tunisia; \\ yasmine.snene.manzli@gmail.com \\ * ahmedjeribi07@yahoo.fr
}

Received: 29 September 2020; Accepted: 29 October 2020; Published: 30 October 2020

\begin{abstract}
In this paper, we discuss the behavior of stock market returns in Tunisia during the COVID19 outbreak. Using the OLS regression, we find that Bitcoin act as a hedge and Ethereum as a diversifier for Tunisia's stock market before the COVID-19 outbreak; however, Bitcoin and Ethereum cannot generate benefits from portfolio diversification and hedging strategies for financial investors during the COVID-19. Moreover, Dash, Monero, and Ripple act as hedges before the COVID-19 outbreak and as diversifiers during this pandemic. Our results reveal that gold acts as a hedge and diversifier before the pandemic, but it's neither hedge nor a haven during the COVID-19 pandemic. Besides, the results indicated that the expected volatility of the US stock market has an impact on the Tunisian stock market. Finally, our results indicate that the growth rate of the COVID-19 confirmed cases and deaths harms Tunisia's stock market.
\end{abstract}

Keywords: Tunisian stock market, cryptocurrencies, Gold, VIX, WTI, COVID-19 cases and deaths, OLS regression.

JEL codes: $C 22, C 5, G 1$

\section{Introduction}

According to the World Health Organization (WHO, 2020), the outbreak of the COVID-19 which appeared in Central China at the end of December 2019 spread to 216 countries, resulting in over 8.3 million confirmed cases and over 450,000 deaths worldwide. Given the widespread and continuous transmission of the novel Coronavirus worldwide, the WHO officially declared it as a pandemic on 11 March 2020.

The pandemic can trigger several channels, including, for example, labor markets, global supply chains, consumption patterns, all of which can affect the global economy. One of the most important components of these channels is certainly the stock markets (see, for example, Al-Awadhi et al., 2020; Ahmar and Del Val, 2020; among others). Global financial markets faced tremendous uncertainties during the latest outbreak of the COVID-19. Stock markets in the US, for instance, have hit four circuit breakers in two weeks. Crude oil prices have fallen to less than $\$ 20$ a barrel, a low record since the beginning of the new century. Most unexpectedly, on April 20, 2020, the crude oil future of West Texas Intermediate (WTI), the US crude benchmark, closed at $-\$ 37.63$ a barrel, an unusual event that would have a significant effect on policymakers and practitioners. Zhang et al. (2020) argue that given the global expansion of the COVID-19, financial markets around the world have reacted to growing risks and shifting inter-market linkages. In another study, Zhang et al. (2020) concluded that the instability 
and economic damages caused by the pandemic led the financial market to be highly unpredictable and volatile. Al-Awadhi et al. (2020) also stated that daily growth in both the total number of cases and deaths is negatively correlated with the stock market return.

Unlike previous financial crises, the underlying forces behind the current crisis are more complicated than ever before. According to Gates (2020), the epidemic of COVID-19 has deemed a "once-in-a-century" pandemic. To contain this highly contagious virus, countries around the world have implemented extensive measures, including the closure of cities and border closures, which have resulted in a temporary economic suspension in many places. Severe acute respiratory syndrome, best known as SARS, was expected to cost the world between \$30-100 billion in 2003 (Smith, 2006). The outbreak of COVID-19 is expected to have a much larger impact on the global economy (Ji et al., 2020). Fernandes (2020), for instance, estimates that the pandemic could cause a median economic slowdown of $2.8 \%$, while the extreme case, such as Spain, could drop by more than $15 \%$. With many uncertainties as to whether the virus will be completely regulated or not, financial markets are likely to encounter further problems and other relevant concerns call for further investigation (Goodwell, 2020). In the wake of big losses, the need to seek safe-haven properties has resurfaced for both practitioners and researchers.

In recent years, various studies are motivated by the popularity of cryptocurrencies through their diversification, hedging, and haven properties (Bouri et al., 2017; Corbet et al., 2018; Urquhart and Zhang, 2019; Smales, 2019; Shahzad et al., 2019; Aysan et al., 2019; Kliber et al., 2019; Guesmi et al., 2019). When investors introduce an asset to their portfolios that decreases losses in periods of market distress by more than hedge or diversifier assets, the magnitude of shocks will reduce and thus improve capital markets' stability. To distinguish a safe-haven asset from a hedge and a diversifier asset, Baur and Lucey (2010) present a definition for each type. A hedge is a commodity that is not correlated or negatively correlated, on average, with another commodity or a portfolio. It may not have the specific property of minimizing losses in periods of market distress or turmoil as the asset may show a positive correlation in such times and a negative correlation in normal times. A diversifier is a commodity that is positive but not perfectly correlated, on average, with another commodity or a portfolio. Similarly to the hedge, it does not reduce losses in extreme adverse market situations as the correlation characteristic is only required to hold on average. However, a safe-haven is a commodity that is not correlated or negatively correlated with another commodity or a portfolio in periods of market distress or turmoil (i.e. the correlation needs to be zero or negative in such times). Contrarily to the hedge and diversifier assets, it has the specific property of minimizing losses in extreme adverse market conditions.

The first thing to remember is that the definition of a haven asset (Baur \& McDermott, 2016) is quite distinct from that of a safe asset (Gorton et al. 2012). While the need to hedge or diversify an investment portfolio is still met, safe-haven investments are mainly relevant at periods of market collapse or recession (Baur \& Lucey, 2010; Baur \& McDermott, 2010). To qualify as a haven asset, a commodity must be able to maintain or raise its value in the case of a market downturn. Statistically, returns from a haven asset should be non-correlated or negatively correlated with returns from other assets during the crisis period to compensate investors for losses when the other assets or portfolio prices falls (Baur \& Lucey, 2010). In other words, a haven asset is a place of safety that provides shelter for investors (i.e. non-negative returns) in extreme market situations. Gold was considered a haven asset under such a notion, despite its traditional position as natural money or a store of value (Bouri et al., 2020). A large volume of literature examines empirically whether gold can function as a haven asset, but the findings are mixed. For example, Baur and McDermott (2010) use 30 years of data from large emerging and developing countries to test the safe-haven assets hypothesis of gold. They confirm this gold property for the US and big stock markets in Europe but not for other markets (such as the case of Tunisia). Reboredo (2013) concludes that gold can play both a hedging role and an effective haven role. Similar findings are also found in Beckmann et al. (2015). In the meanwhile, Hood and Malik (2013) indicate that gold is a hedge for the U.S. stock market but its position as a haven is weak compared to the VIX. In a time-varying framework, Lucey and Li (2015) study the role of precious 
metals as safe havens and find that the haven strength of gold changes over time. Ji et al. (2020) argue that the position of a haven is less effective for most of the assets they studied (including Bitcoin), and gold remains robust as a safe-haven asset during the COVID-19 outbreak. Further, Conlon and McGee (2020) and Corbet et al. (2020) argued that gold and cryptocurrencies are not hedges or safe havens at a period of financial or economic turmoil, but rather are the contagion amplifiers. Besides, Cheema et al. (2020) compared the performance of safe-haven assets during two stressful stock market regimes which are the 2008 Global Financial Crisis (GFC) and the COVID-19 pandemic. Among their results, they find that gold acts as a haven during the GFC, but it fails to protect investors' wealth during the COVID-19 outbreak, suggesting that investors should choose liquid and stable commodities rather than gold during a pandemic. They also find that Bitcoin does not serve as a haven during the COVD19 pandemic.

Cryptocurrency is another famous safe-haven asset candidate. For instance, Bitcoin was introduced as a decentralized digital currency by Nakamoto (2008). Its special existence makes Bitcoins independent of any single central bank or government. Baur et al. (2018) statistical study suggest that Bitcoin is uncorrelated to other financial assets. Bouri et al. (2019) find that cryptocurrencies can be used in equity investment as hedges against downside risk. This property extends to normal times and periods of crisis, which makes Bitcoin compliant with the idea of a haven. However, opinions about Bitcoin's role are often on the opposite side. Klein et al. (2018) compare Bitcoin's statistical properties with other asset groups, and their portfolio research shows that Bitcoin isn't a safe-haven asset and can't even hedge (protect) against the risk for developed markets. Smales (2019) claims that Bitcoin should not even be considered as a possible safe asset. Shahzad et al. (2019) suggest the idea of a weak/strong haven and analyze the role of Bitcoin, gold, and commodities for stock market indices. They use Han et al. (2016) cross-quantilogram for the 2010 to 2018 data and their key findings indicate that to certain indices, Bitcoin has poor safe-haven properties but its function changes over time.

Many studies indicated that digital currencies can serve not only as a store of value during market volatility but also as a means of portfolio diversification. For instance, Gil-Alana et al. (2020) described the potential position of cryptocurrencies in investment portfolios as a major diversification choice for investors, with a specific focus on Bitcoin and Ethereum. Moreover, Liu (2019) established the portfolio gains from cryptocurrency inclusion. When specifically analyzing the market interaction between cryptocurrencies and other conventional financial assets, Bouri et al. (2017) found that Bitcoin is a weak hedge and is only appropriate for diversification purposes, a finding that was repeated when considering the S\&P500 exchange (Tiwari et al., 2019) and Eurostoxx 50, Nikkei 225 and CSI 300 (Feng et al., 2018). More recently, Conlon and McGee (2020) indicate that Bitcoin was neither a haven nor a hedge against the intense bear market in the S\&P500 caused by the COVID-19 pandemic. Also, Corbet et al. (2020a) studied the relationships between the largest cryptocurrencies during the COVID-19 pandemic and they find proof of strong growth in both returns and volumes exchanged, suggesting that during this time of exceptional financial market turmoil, large cryptocurrencies operated as a store of value. While not only offering investors diversification benefits, results also showed that similar to that of precious metals during historic crises, these digital assets acted as a safe-haven. Based on the study of Baur and Lucey (2010), we tested the impact of the COVID-19 global pandemic by addressing this specific question: how cryptocurrencies, VIX, Oil, and gold prices, as well as the number of COVID-19 cases and deaths, impact the Tunisian stock market? Example of a developing country. In this case, we examined the safe-haven properties of digital and financial assets regarding the Tunisian stock market indices using the OLS regression for the period ranging from 31 December 2019, to 30 April 2020 and divided into two sub-periods (before and during the COVID-19 outbreak) to reflect the impact of the 2020 global pandemic. The findings revealed that cryptocurrencies (Bitcoin, Ethereum, Dash, Monero, and Ripple) and gold act as hedges and diversifiers before the COVID-19 outbreak while only Dash, Monero, and Ripple act as diversifiers during the COVID-19 pandemic, and gold doesn't have the haven property during this pandemic. Also, the results indicated that the expected volatility of the US stock market has an impact on the Tunisian stock market and the oil index can be considered as a haven asset. Also, our results indicated that the growth rate of the COVID-19 
confirmed cases and deaths hurts Tunisia's stock market. To the best of our knowledge, this is the first paper to examine the impact of the COVID-19 pandemic on the Tunisian stock market and it is also the first that studies the introduction of cryptocurrencies in Tunisia and treats their haven properties using the OLS regression.

The rest of the paper is organized as follows. Section 2 explores the Tunisian stock market during the COVID-19 pandemic. Section 3 presents the methodology and data. Section 4 discusses the results. Section 5 concludes.

\section{Tunisia's Stock Market and COVID-19}

When the first reported case was documented outside of China - the epicenter of the outbreak on 13 January 2020, the Tunisian government put in place its response plan and measures built on a containment strategy to mitigate the health, economic, and social effects on the Tunisian economy. This included detecting imported COVID-19 cases, and both tracking and isolating exposed connections. On 2 March 2020, a person who had recently traveled from Italy self-reported symptoms and was identified as the first COVID-19 case in Tunisia. Shortly afterward, the government applied strict security controls on travelers. On 16 March, the Tunisian Head of Government announced the implementation of the following measures: the closing of territory, air, and sea borders, the ban on all public meetings, and the reduction of regular office hours to five hours. This was followed by the Presidential Decree 6 PM to 6 AM Curfew. At that time, only 24 positive COVID-19 cases were reported, of which 14 were imported. These early measures were supported by their possible effect on the regulation of the spread of the virus across the country. After that, a general lockdown was agreed upon by the President of Tunisia after a meeting of the National Security Council on 20 March. Nonetheless, as of 1 May 2020, 998 cases had been reported in the country, of which 41 died, 316 recovered, and 641 remain under treatment.

The current health crisis facing our country is serious and will further worsen the financial and economic downturn. In particular, the COVID-19 crisis can illustrate the rise in the unemployment rate. This is demonstrated by the fact that many large companies and small and medium-sized firms were forced to suspend their activities during the crisis period. Government and financial institutions should then intervene to control the market and ensure the long-term survival of those companies. Within this context, the Governing Council of the Tunisian Central Bank (TCB) has agreed to reduce the interest rate on the money market by 100 basis points. It was 7.84 percent in February 2020 and became 6.75 percent on 18 March 2020, as it is illustrated in the following picture:

Figure 1. Changes in Money Market Interest Rate

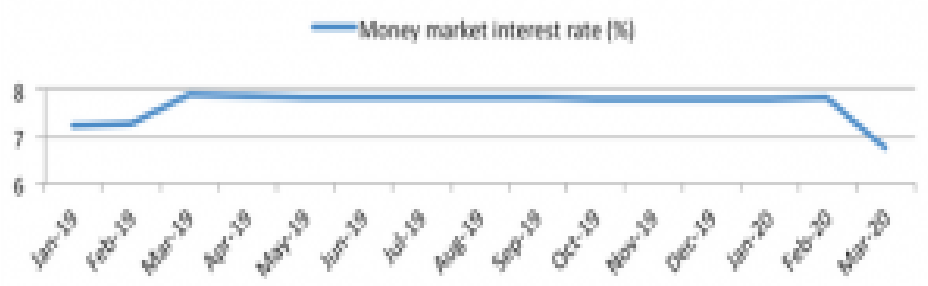

Source: Tunisian Central Bank (TCB)

The TCB has also introduced some other exceptional steps intended to reduce the economic and social spillovers from the Covid-19 crisis. Indeed, the Board of Directors agreed to reduce the financial cost of individual loans, helping them to raise their buying power. It also agreed to provide liquidity to banks that will allow them to continue their operations even during these turbulent times.

Also, the Tunindex stood at the same pace for the first quarter of 2020 as for 2019. The banking sector continues to rise at 7.6 percent in the first quarter of 2020, while the leasing sector has decreased 
by 5.8 percent due to many reasons, including monetary policy and the agro-food industry, which have risen by 3 percent. The Tunis Stock Exchange has resisted more than any other stock exchange in the world. Referring to the effects of the spread of the pandemic, the Tunis Stock Exchange has experienced a decline of 10.5 percent since the beginning of 2020, though defining this decline as very moderate relative to the behavior of other exchanges across the world since the coronavirus spread. The stock markets of many countries have been fallen until 13 May, including Morocco (-22\%), Egypt (-26\%), Saudi Arabia (-21\%), France (-25\%), and Germany (-19\%).

\section{Methodology and Data}

Since the appearance of the COVID-19 pandemic, the global economy witnessed significant changes that caused several stock market crashes. In this study, we are trying to examine the responses of the Tunisian stock market indices prices to the increased number of cases and deaths caused by the COVID-19. We also studied the impact of changes in the cryptocurrencies and gold prices, which are considered safe-havens in many studies, as well as the VIX and WTI indexes. Our regression is as follows:

$$
\begin{gathered}
\operatorname{INDEX}_{t}=\alpha_{0}+\alpha_{1} \text { CRYPTO }_{t}+\alpha_{2} \text { VIX }_{t}+\alpha_{3} \text { WTI }_{t}+\alpha_{4} G O L D_{t}+\varepsilon_{t} \\
\text { INDEX }_{t}=\alpha_{0}+\alpha_{1} \text { CRYPTO }_{t}+\alpha_{2} V I X_{t}+\alpha_{3} \text { WTI }_{t}+\alpha_{4} \text { GOLD }_{t}+\alpha_{5} C C_{t}+\alpha_{6} C D_{t}+\varepsilon_{t}
\end{gathered}
$$

With:

$I N D E X_{t}$ : The daily return of the studied index;

$V I X_{t}$ : The daily return of the VIX index, as a measure of the expected volatility of the US stock market;

$W T I_{t}$ : The daily return of the WTI crude oil;

$G O L D_{t}$ : The daily return of GOLD;

$C C_{t}$ : The growth rate of confirmed COVID-19 cases;

$C D_{t}$ : The growth rate of confirmed COVID-19 deaths.

Our data consists of 85 daily observations on closing prices $\left(p_{t}\right)$. the cryptocurrencies prices (Bitcoin, Dash, Monero, Ethereum, and Ripple) were collected from the Coin Market Cap basis while gold, WTI, and VIX prices were collected from the database DataStream. The Tunisian stock market indices prices which are Tunisia's stock exchange benchmark index "TUNINDEX", Tunisia's benchmark index containing 20 companies "TUNIDEX20", Banks "TUNBANK", Industrial index "TUNIND", Food and beverage "TUNALIM", Insurance "TUNASS", Basic materials "TUNBASE", Construction "TUNCONST", Financials "TUNFIN", Automobile \& parts "TUNAUTO", Distribution "TUNDIS", Building construct materials "TUNBATIM", Consumer services "TUNSAC", financial services "TUNSEFI", were collected from the Tunis Stock Exchange (TSE) database while the number of cases and deaths was collected from the European Centre for Disease Prevention and Control (An agency of the European Union). The study period is ranging from December 31, 2019, to April 30, 2020. It is divided into two sub-periods to reflect the impact of the 2020 global pandemic. The first subperiod is the period preceding the outbreak of the COVID-19 and it goes from 31 December 2019 to 28 February 2020. The second one is the period during the COVID-19 outbreak and it goes from 02 March 2020 (first case of Coronavirus reported in Tunisia) to 30 April 2020. Daily returns are defined with logarithmic returns such that:

$$
r_{t}=\ln \left(\frac{p_{t}}{p_{t-1}}\right)
$$

Where:

$r_{t}$ : The logarithmic return

$p_{t}$ : The price at time $t$

$p_{t-1}$ : The price at time $\mathrm{t}-1$ 
This transformation of data is usually used to obtain a stationary series, as it is shown in figures 2 and 3. The two figures show that the series is highly volatile, but it is more volatile during the COVID19 outbreak than during the period before the COVID-19. Noticeably, all the series returns reached their negative peaks since the beginning of March and during April, forming a downturn financial bubble. This is due to the increased spread of the virus that started to hit investors' confidence, thus prompting a record plunge in the stock market. Before the COVID-19 pandemic, the five cryptocurrencies (Bitcoin, Ethereum, Dash, Monero, and Ripple) has shown relative calm with lower volatility. However, after the appearance of COVID-19, the cryptocurrency market became more volatile. Bitcoin is considered the less volatile among all, while Monero and Ripple are the most volatile.

Gold is usually considered an effective haven during extreme market conditions (Baur and Lucey, 2010) and is generally less volatile than other commodities; however, during the 2020 pandemic, the yellow metal has shown high volatility, which means that gold is not playing the role of a haven that it has always performed before. The VIX index is highly volatile during the entire period (before and during the COVID-19), while the Oil index prices were stable during the period before the COVID-19 and became volatile with the appearance of the pandemic.

Concerning the Tunisian stock market indices, the volatility of the two benchmark indexes (TUNINDEX and TUNINDEX20), TUNBANK, and TUNFIN was low before the COVID-19 outbreak and became high since the emergence of the pandemic in the country. However, the rest of the indexes show extremely high volatility during the entire period.

\section{Results}

The descriptive statistics of cryptocurrencies, Tunisian stock market indices, and asset returns for the two sub-periods before and during the COVID-19 outbreak are reported in Tables 1 and 2.

From Table 1, results indicate that before the COVID-19 pandemic all cryptocurrencies, as well as Gold and VIX, have positive mean value. However, most of the Tunisian stock market indices, as well as WTI have negative mean value. The highest mean value is taken by the VIX index (0.0267); whereas, the lowest mean value is taken by the WTI index (-0.0075).

The standard deviations for all series are higher than their mean suggesting a higher level of risk in these markets. Between all assets, Gold presents the lowest risk (1\%); the main reason that explains why gold is usually referred to as a safe-haven commodity by investors. It is followed by WTI $(1.87 \%)$ and VIX presents the highest risk (10.85\%). For cryptocurrencies, Bitcoin presents the lowest risk $(3.17 \%)$ followed by Ethereum $(4.76 \%)$ and Dash presents the highest risk $(11.61 \%)$. However, for the Tunisian stock market indices, TUNINDEX presents the lowest risk $(0.35 \%)$, followed by TUNINDEX20 (0.42\%) and TUNASS presents the highest risk $(0.87 \%)$.

All returns (cryptocurrencies and financial assets) have kurtosis values higher than three (except for Bitcoin, TUNSEF, TUNBASE, and TUNBATIM) and the distribution of returns is negatively and positively skewed for all assets which indicate that all returns are far from the normal distribution, therefore, the assumption of Gaussian returns is rejected by the Jarque-Bera (1987) test for all assets.

Table 2 shows that during the COVID-19 outbreak, all cryptocurrency and Tunisian stock market mean returns became negative compared to those during the pre-coronavirus period. The results indicate that the highest mean of growth rates is for Tunisia's confirmed number of COVID-19 cases followed by the country's confirmed number of COVID-19 deaths. Whereas, TUNASS proved the lowest mean return and followed by the WTI index.

The standard deviations for all series are higher than their mean and higher than those during the pre-coronavirus period suggesting a higher level of risk. During this pandemic, the highest risk-return is taken by Tunisia's confirmed number of COVID-19 cases and deaths, respectively $22.12 \%$ and $14.54 \%$. Between all the assets, Gold presents the lowest risk (1.82\%), while the WTI index presents the highest risk (15.62\%). For cryptocurrencies, Ripple presents the lowest risk $(8.39 \%)$ followed by Bitcoin $(9.34 \%)$, while Ethereum presents the highest risk (11.63\%). However, for the Tunisian stock market 
indices, TUNSEFI presents the lowest risk $(0.52 \%)$ followed by TUNASS $(0.93 \%)$, and TUNAUTO presents the highest risk (2.12\%).

All returns (cryptocurrencies and financial assets) have kurtosis values higher than three (except for TUNIND, TUNSEFI, TUNASS, TUNAUTO, and TUNBATIM) and the distribution of returns is negatively and positively skewed for all assets which indicate that all returns are far from the normal distribution, therefore, the assumption of Gaussian returns is rejected by the Jarque-Bera (1987) test for all assets.

Figure 2. Cryptocurrencies' Volatility Before and During The COVID-19 Outbreak

BITCOIN

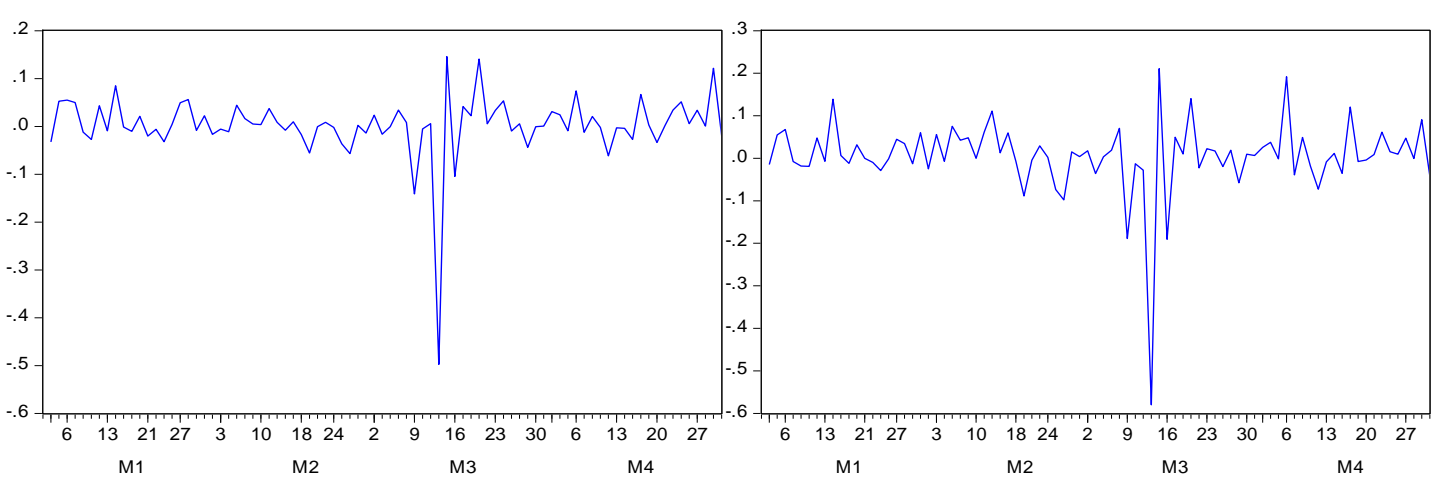

DASH

MONERO

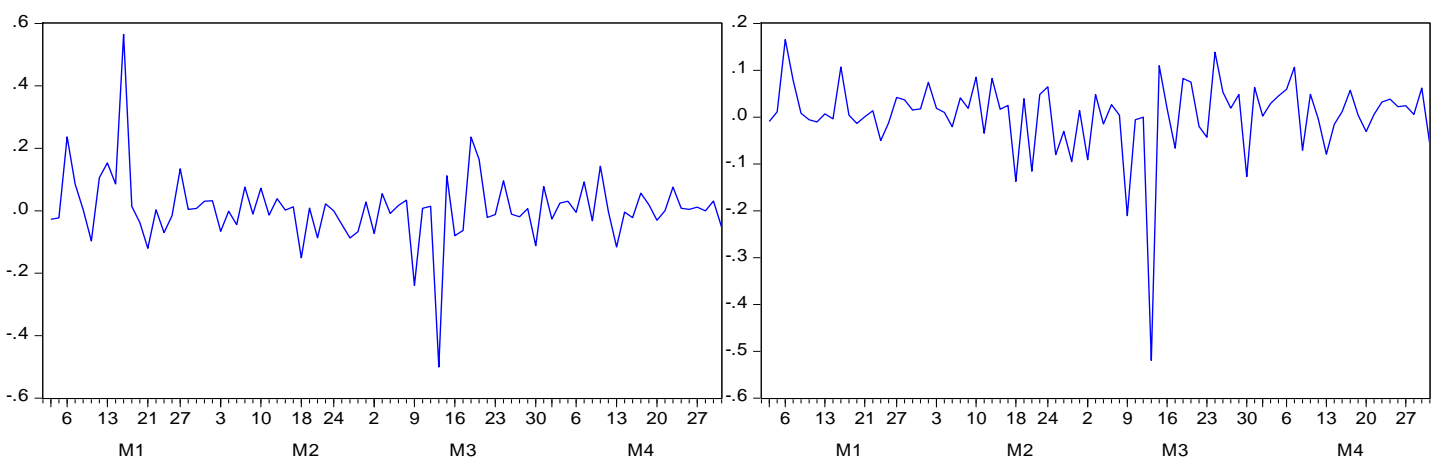

RIPPLE

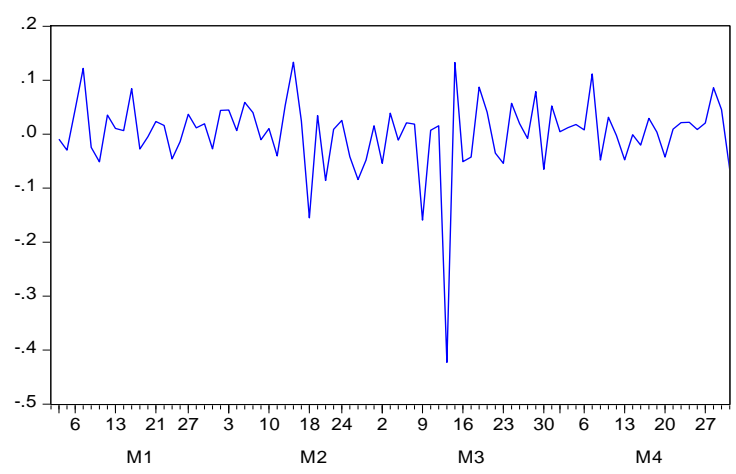


Figure 3. Gold, VIX, WTI, and Tunisian Stock Market Indices' Volatility Before and During The COVID-19 Outbreak

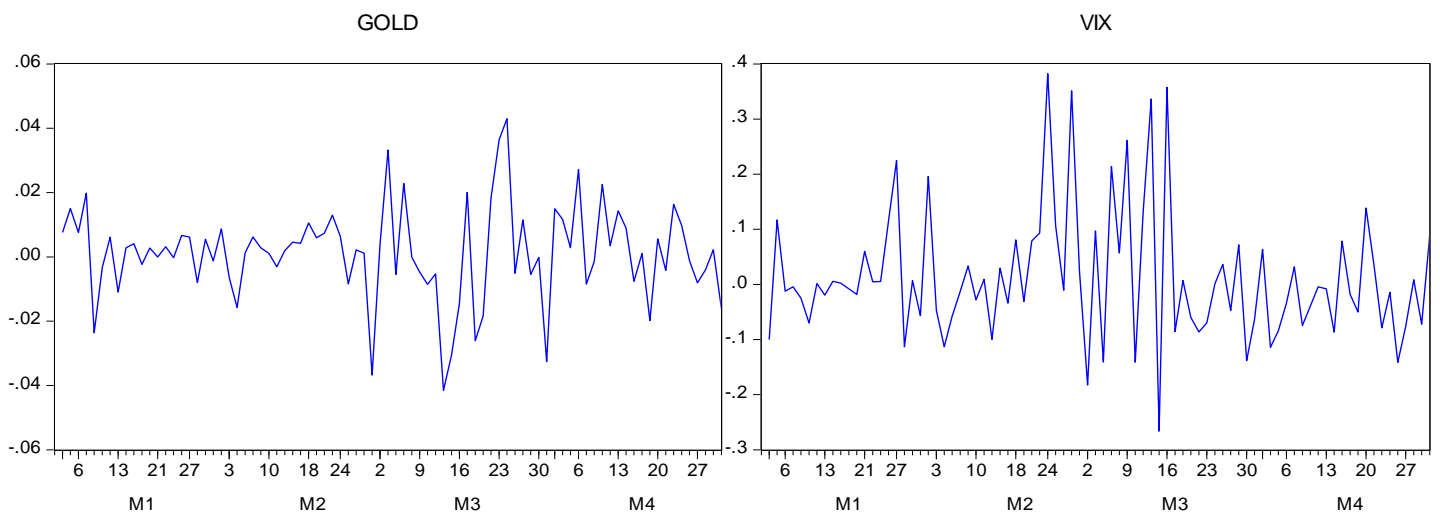

WTI

TUNINDEX
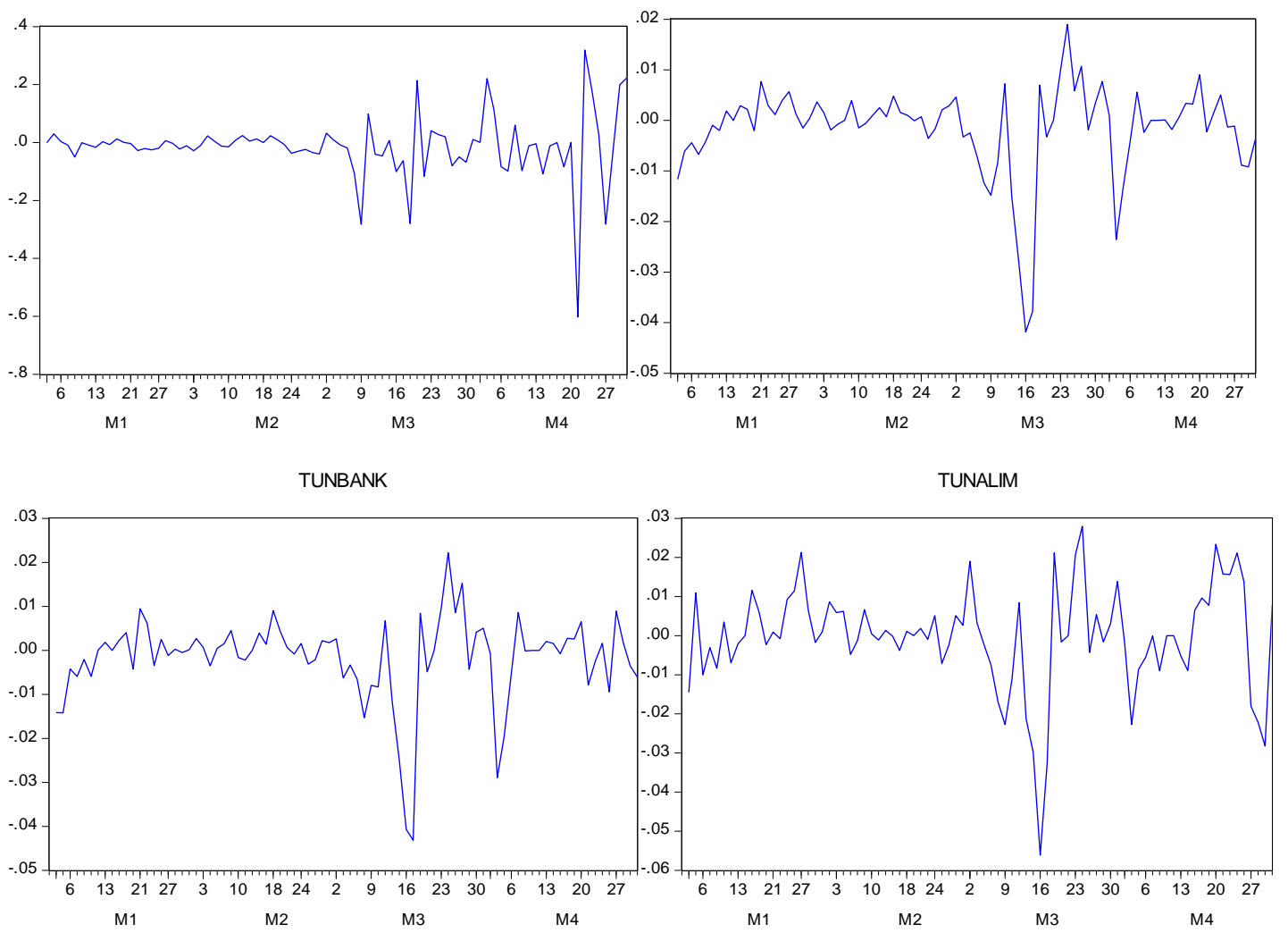

TUNASS TUNAUTO

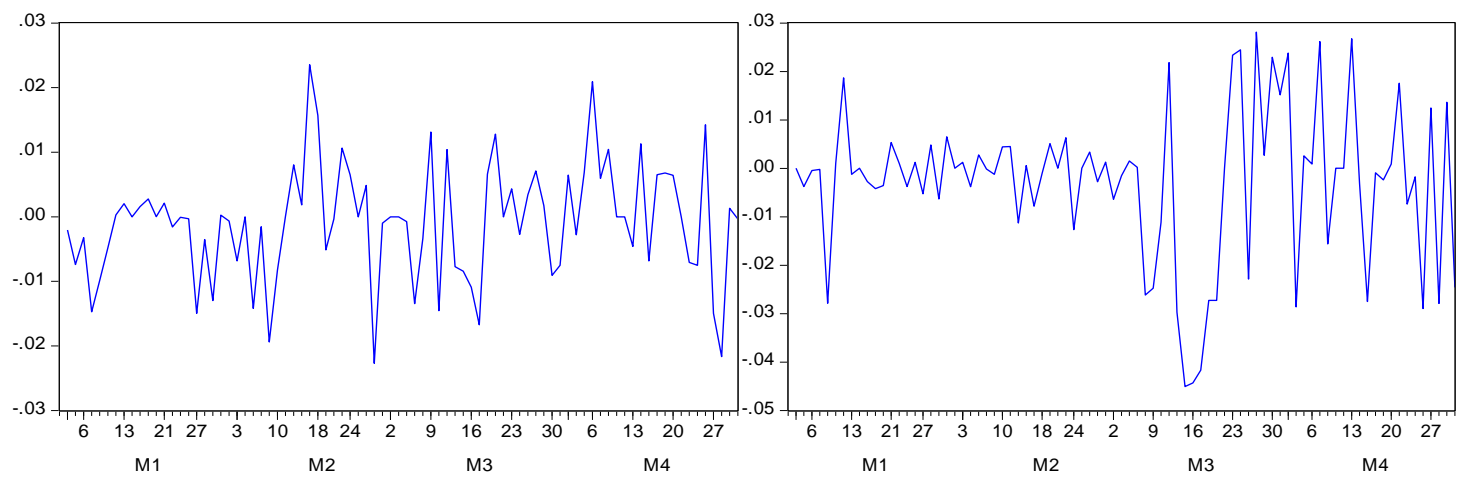


TUNFIN

TUNBASE

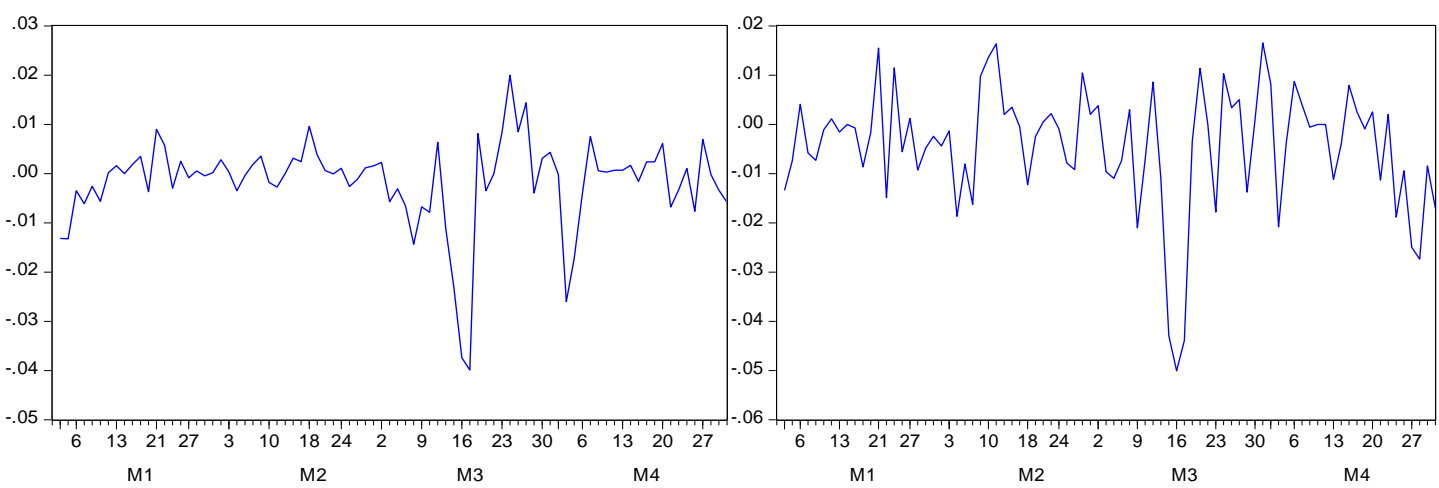

TUNBATIM

TUNCONS

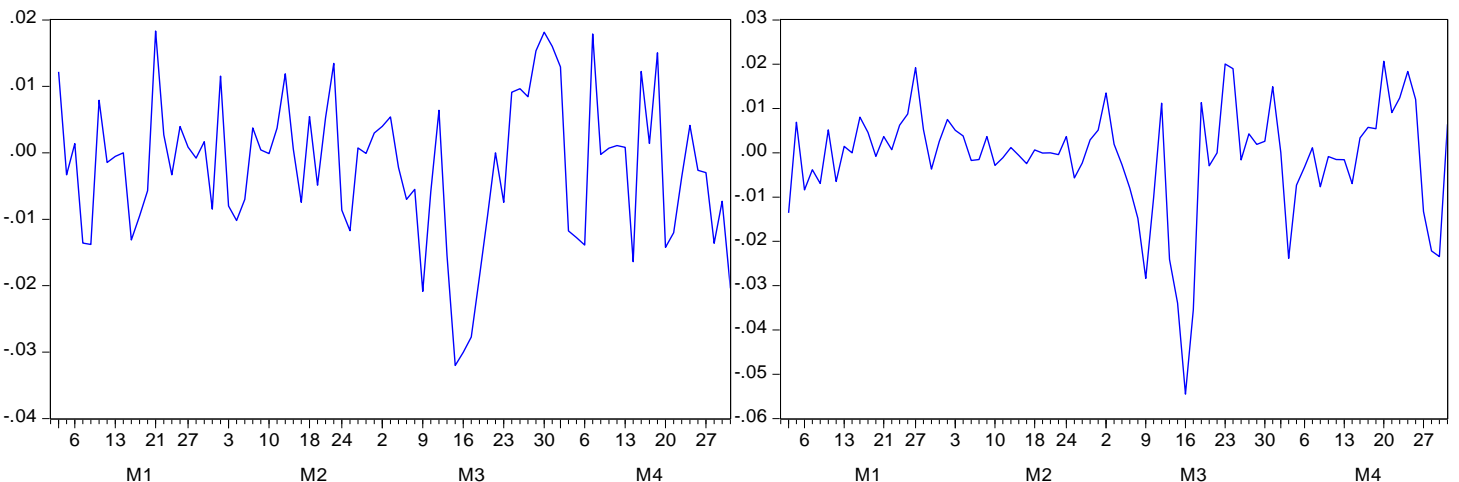

TUNDIS

TUNIND

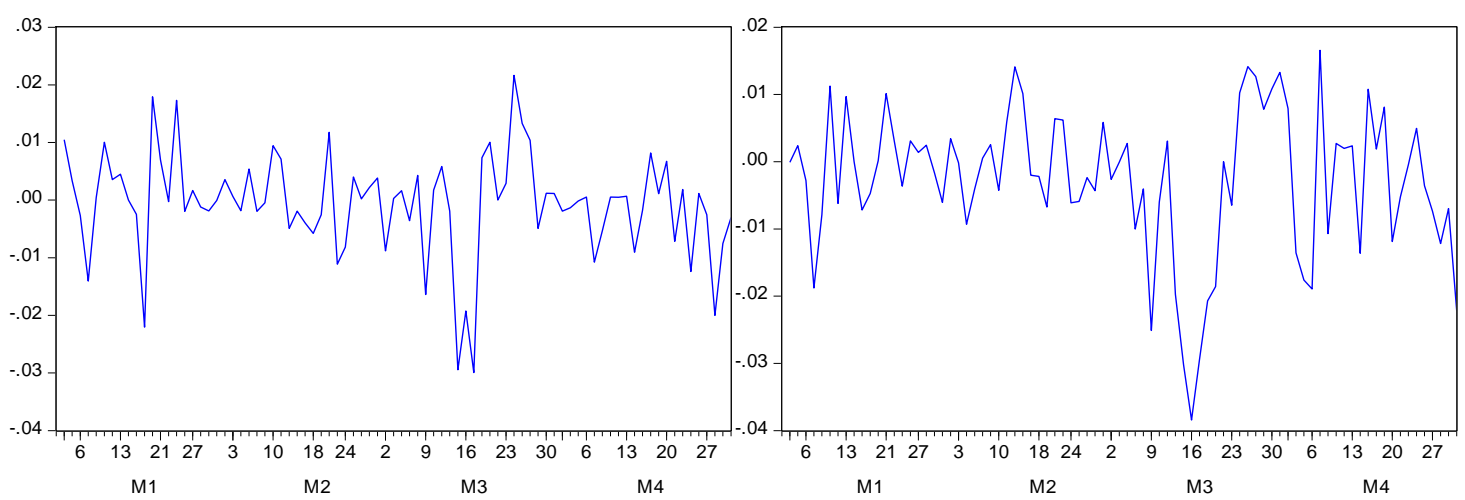

TUNSAC

TUNSEFI

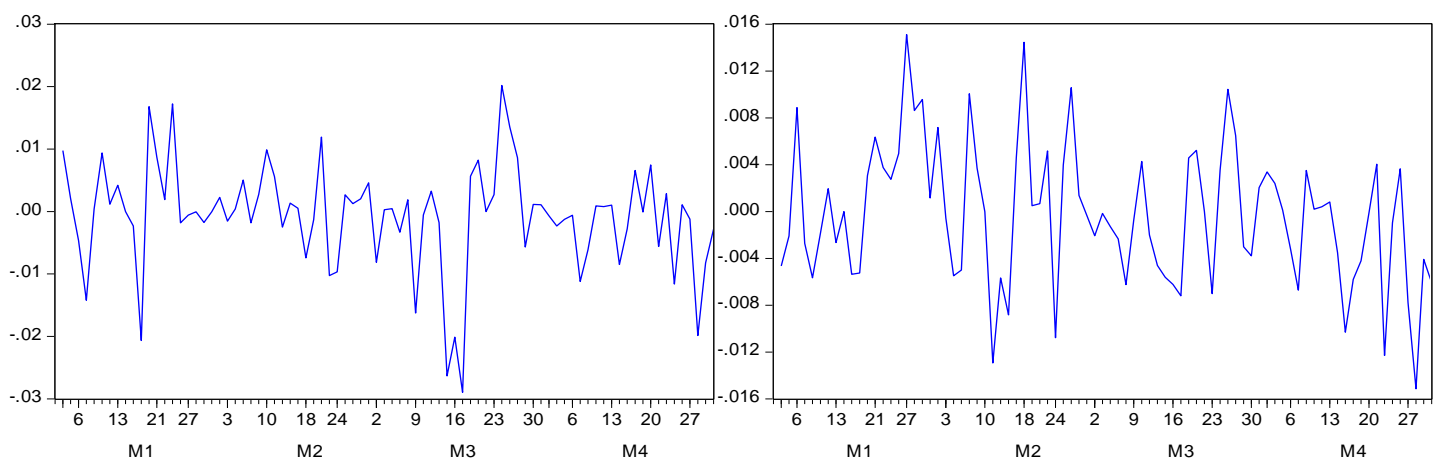


Table 1. Descriptive Statistics Summary for Returns Before The COVID-19 Outbreak

\begin{tabular}{|c|c|c|c|c|c|c|c|}
\hline & Mean & Max & Min & Std. Dev. & Skewness & Kurtosis & $\mathrm{J}-\mathrm{B}$ \\
\hline \multicolumn{8}{|c|}{ Cryptocurrency Market } \\
\hline BITCOIN & 0.0047 & 0.0847 & -0.0570 & 0.0317 & 0.4127 & 2.8722 & $1.1628^{* * *}$ \\
\hline DASH & 0.0190 & 0.5648 & -0.1506 & 0.1161 & 2.7164 & 13.4973 & $232.8529^{*}$ \\
\hline ETHEREUM & 0.0141 & 0.1391 & -0.0978 & 0.0476 & 0.0721 & 3.6536 & $0.7469^{* * *}$ \\
\hline MONERO & 0.0106 & 0.1657 & -0.1371 & 0.0575 & -0.1844 & 4.1283 & $2.3485^{* * *}$ \\
\hline RIPPLE & 0.0053 & 0.1334 & -0.1550 & 0.0535 & -0.2776 & 4.3265 & $3.4471^{* * *}$ \\
\hline \multicolumn{8}{|c|}{ Commodity Market } \\
\hline GOLD & 0.0011 & 0.0197 & -0.0367 & 0.0100 & -1.6443 & 7.1011 & $46.0594^{*}$ \\
\hline VIX & 0.0267 & 0.3821 & -0.1131 & 0.1085 & 1.6445 & 5.8992 & $32.0400^{*}$ \\
\hline WTI & -0.0075 & 0.0301 & -0.0505 & 0.0187 & -0.1111 & 2.5662 & $0.3959^{* * *}$ \\
\hline \multicolumn{8}{|c|}{ Tunisian Stock Market indices } \\
\hline TUNINDEX & 0.00017 & 0.0076 & -0.0116 & 0.0035 & -0.8799 & 4.7162 & $10.0714^{* *}$ \\
\hline TUNINDEX20 & 0.00012 & 0.0075 & -0.0132 & 0.0042 & -0.7850 & 4.0358 & $5.8966^{* *}$ \\
\hline TUNBANK & -0.00019 & 0.0094 & -0.0141 & 0.0047 & -0.9003 & 5.1380 & $13.0236^{*}$ \\
\hline TUNIND & -0.00019 & 0.0141 & -0.0187 & 0.0065 & -0.0620 & 3.3671 & $0.2502^{* * *}$ \\
\hline TUNFIN & -0.00018 & 0.0095 & -0.0132 & 0.0044 & -0.8005 & 5.1710 & $12.1282^{*}$ \\
\hline TUNSAC & 0.0010 & 0.0172 & -0.0206 & 0.0073 & -0.3475 & 4.3392 & $3.7946^{* * *}$ \\
\hline TUNSEFI & 0.0012 & 0.0151 & -0.0129 & 0.0065 & 0.0754 & 2.6479 & $0.2445^{* * *}$ \\
\hline TUNALIM & 0.0014 & 0.0212 & -0.0144 & 0.0066 & 0.3473 & 3.9247 & $2.2299^{* * *}$ \\
\hline TUNASS & -0.0018 & 0.0235 & -0.0226 & 0.0087 & 0.1162 & 4.2438 & $2.6688^{* * *}$ \\
\hline TUNAUTO & -0.0007 & 0.0186 & -0.0278 & 0.0068 & -1.1393 & 8.6298 & $61.4805^{*}$ \\
\hline TUNBASE & -0.0018 & 0.0163 & -0.0186 & 0.0083 & 0.2857 & 2.8617 & $0.5761^{* * *}$ \\
\hline TUNBATIM & -0.0005 & 0.0183 & -0.0138 & 0.0078 & 0.2672 & 2.6533 & $0.6762^{* * *}$ \\
\hline TUNCONS & 0.0010 & 0.0192 & -0.0135 & 0.0056 & 0.2945 & 4.7976 & $5.9640^{* *}$ \\
\hline TUNDIS & 0.0008 & 0.0179 & -0.0220 & 0.0075 & -0.2986 & 4.4206 & $3.9584^{* * *}$ \\
\hline
\end{tabular}

Note: ${ }^{*}{ }^{* *}$ and ${ }^{* * *}$ means significant at $1 \%, 5 \%$ and $10 \%$ level of significance respectively. St.dev represents the standard deviation of returns and J-B Stat indicates the Jarque-Bera statistics.

Table 2. Descriptive Statistics Summary for Returns During The COVID-19 Outbreak

\begin{tabular}{cccccccc} 
& Mean & Max & Min & Std. Dev. & Skewness & Kurtosis & J-B \\
\cline { 2 - 8 } & \multicolumn{7}{c}{ Cryptocurrency Market } \\
\cline { 2 - 8 } BITCOIN & -0.0006 & 0.1459 & -0.4972 & 0.0934 & -3.4705 & 19.9675 & $602.1390^{*}$ \\
DASH & -0.0009 & 0.2358 & -0.5002 & 0.1098 & -2.1156 & 11.7949 & $170.6674^{*}$ \\
ETHEREUM & -0.0027 & 0.2106 & -0.5798 & 0.1163 & -2.7872 & 15.6704 & $343.3087^{*}$ \\
MONERO & -0.0005 & 0.1385 & -0.5195 & 0.1024 & -3.2388 & 16.7531 & $414.0746^{*}$ \\
RIPPLE & -0.0016 & 0.1326 & -0.4225 & 0.0839 & -2.9771 & 16.0877 & $370.4154^{*}$ \\
\hline & & & Commodity Market & & & $0.0037^{*}$ \\
GOLD & 0.0013 & 0.0429 & -0.0415 & 0.0182 & 0.0224 & 3.0100 & $9.7110^{*}$ \\
VIX & 0.0005 & 0.3575 & -0.2662 & 0.1259 & 0.9839 & 4.2440 & $25.5273^{*}$ \\
WTI & -0.0211 & 0.3196 & -0.6016 & 0.1567 & -0.9227 & 6.2926 & $23.0334^{*}$ \\
\hline TUNINDEX & -0.0034 & 0.0189 & -0.0418 & 0.0120 & -1.3775 & 5.2947 & $22.6176^{*}$ \\
TUNINDEX20 & -0.0039 & 0.0201 & -0.0478 & 0.0136 & -1.3892 & 5.2143 & $19.3530^{*}$
\end{tabular}




\begin{tabular}{cccccccc} 
TUNIND & -0.0051 & 0.0165 & -0.0384 & 0.0134 & -0.4380 & 2.4725 & $1.8734^{* * *}$ \\
TUNFIN & -0.0031 & 0.0199 & -0.0398 & 0.0117 & -1.2759 & 5.2551 & $20.7796^{*}$ \\
TUNSAC & -0.0022 & 0.0201 & -0.0289 & 0.0095 & -0.7836 & 4.3169 & $7.5089^{* *}$ \\
TUNSEFI & -0.0017 & 0.0104 & -0.0151 & 0.0052 & -0.1953 & 2.9946 & $0.2736^{* * *}$ \\
TUNALIM & -0.0026 & 0.0279 & -0.0561 & 0.0173 & -0.6535 & 3.6259 & $3.7627^{* * *}$ \\
TUNASS & $-9.82 \mathrm{e}-05$ & 0.0209 & -0.0216 & 0.0093 & -0.1442 & 2.6001 & $0.4356^{* * *}$ \\
TUNAUTO & -0.0047 & 0.0281 & -0.0450 & 0.0212 & -0.1522 & 1.9704 & $2.0654^{* * *}$ \\
TUNBASE & -0.0070 & 0.0165 & -0.0500 & 0.0148 & -1.1017 & 4.0495 & $10.6725^{*}$ \\
TUNBATIM & -0.0037 & 0.0181 & -0.0320 & 0.0131 & -0.1855 & 2.3682 & $0.9618^{* * *}$ \\
TUNCONS & -0.0033 & 0.0206 & -0.0545 & 0.0163 & -0.9509 & 3.8977 & $7.9249^{*}$ \\
TUNDIS & -0.0019 & 0.0216 & -0.0299 & 0.0100 & -0.8171 & 4.4069 & $8.3315^{*}$ \\
\hline & & Confirmed COVID-19 cases and deaths & & $32.5819^{*}$ \\
\hline (CC) & 0.1639 & 0.9162 & 0.0000 & 0.2212 & 1.7690 & 5.4697 & $20.3711^{*}$ \\
\hline (CD) & 0.0925 & 0.5108 & 0.0000 & 0.1454 & 1.7986 & 5.1262 & 2
\end{tabular}

Note: ${ }^{*},{ }^{* *}$ and ${ }^{* * *}$ means significant at $1 \%, 5 \%$ and $10 \%$ level of significance respectively. St.dev represents the standard deviation of returns and J-B Stat indicates the Jarque-Bera statistics. CC and CD respectively means

COVID-19 confirmed cases and Deaths.

In this paper, we empirically study the impact of cryptocurrencies, VIX, Oil, and Gold prices, as well as the increasing rates of COVID-19 cases and deaths on the Tunisian stock market. The OLS regression results are given in Tables 3 and 4 .

Table 3. Estimation of The OLS Regression Result Before The COVID-19 Outbreak

\begin{tabular}{|c|c|c|c|c|c|c|c|c|c|c|}
\hline & $\mathrm{C}$ & Bitcoin & Ethereum & Dash & Monero & Ripple & VIX & WTI & GOLD & $\mathbf{R}^{2}$ \\
\hline \multirow{5}{*}{ 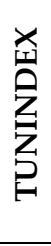 } & 0.0002 & -0.0130 & - & - & - & - & $0.0154^{* *}$ & 0.0432 & $-0.1090^{* * *}$ & 0.1672 \\
\hline & $6.46 \mathrm{E}-05$ & - & 0.0051 & - & - & - & $0.0150^{* *}$ & 0.0324 & $-0.1116^{* * *}$ & 0.1594 \\
\hline & 0.0001 & - & - & 0.0011 & - & - & $0.0153^{* *}$ & 0.0382 & $-0.1154^{* * *}$ & 0.1566 \\
\hline & 0.0001 & - & - & - & -0.0006 & - & $0.0151^{* *}$ & 0.0372 & $-0.1126^{* * *}$ & 0.1553 \\
\hline & 0.0001 & - & - & - & - & 0.0033 & $0.0154^{* *}$ & 0.0374 & $-0.1162^{* * *}$ & 0.1576 \\
\hline \multirow{5}{*}{ 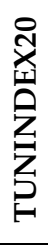 } & 0.0002 & -0.0179 & - & - & - & - & $0.0187^{*}$ & 0.0595 & $-0.1309^{* * *}$ & 0.1744 \\
\hline & $1.63 \mathrm{E}-05$ & - & 0.0072 & - & - & - & $0.0182^{*}$ & 0.0446 & $-0.1344^{* * *}$ & 0.1640 \\
\hline & 0.0001 & - & - & 0.0006 & - & - & $0.0184^{*}$ & 0.0519 & $-0.1380^{* * *}$ & 0.1583 \\
\hline & 0.0001 & - & - & - & -0.0001 & - & $0.0183^{* *}$ & 0.0515 & $-0.1367^{* * *}$ & 0.1581 \\
\hline & 0.0001 & - & - & - & - & 0.0047 & $0.0187^{*}$ & 0.0515 & $-0.1409^{* * *}$ & 0.1615 \\
\hline \multirow{5}{*}{ 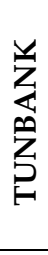 } & -0.0001 & -0.0266 & - & - & - & - & 0.0116 & 0.0234 & -0.0795 & 0.0903 \\
\hline & -0.0002 & - & -0.0012 & - & - & - & 0.0111 & 0.0128 & -0.0888 & 0.0619 \\
\hline & -0.0003 & - & - & 0.0002 & - & - & 0.0111 & 0.0118 & -0.0889 & 0.0618 \\
\hline & -0.0002 & - & - & - & -0.0045 & - & 0.0105 & 0.0102 & -0.0824 & 0.0646 \\
\hline & -0.0003 & - & - & - & - & 0.0071 & 0.0117 & 0.0116 & -0.0945 & 0.0681 \\
\hline \multirow{5}{*}{$\stackrel{\text { 竞 }}{\mathrm{Z}}$} & 0.0012 & -0.0278 & - & - & - & - & 0.0156 & $0.1868^{*}$ & $-0.2474^{* *}$ & 0.1640 \\
\hline & 0.0005 & - & 0.0208 & - & - & - & 0.0146 & $0.1545^{* *}$ & $-0.2496^{* *}$ & 0.1682 \\
\hline & 0.0011 & - & - & -0.0101 & - & - & 0.0133 & $0.1675^{* *}$ & $-0.2385^{* * *}$ & 0.1794 \\
\hline & 0.0010 & - & - & - & -0.0045 & - & 0.0144 & $0.1730^{* *}$ & $-0.2507^{* * *}$ & 0.1493 \\
\hline & 0.0010 & - & - & - & - & -0.0077 & 0.0144 & $0.1745^{* *}$ & $-0.2500^{* * *}$ & 0.1516 \\
\hline \multirow{4}{*}{$\begin{array}{l}\text { Z } \\
\text { Z } \\
\text { Z }\end{array}$} & -0.0001 & -0.0273 & - & - & - & - & 0.0102 & 0.0209 & -0.0590 & 0.0840 \\
\hline & -0.0002 & - & -0.0024 & - & - & - & 0.0096 & 0.0110 & -0.0689 & 0.0507 \\
\hline & -0.0003 & - & - & -0.0002 & - & - & 0.0096 & 0.0085 & -0.0677 & 0.0501 \\
\hline & -0.0002 & - & - & - & -0.0053 & - & 0.0089 & 0.0071 & -0.0612 & 0.0545 \\
\hline
\end{tabular}




\begin{tabular}{|c|c|c|c|c|c|c|c|c|c|c|}
\hline & -0.0003 & - & - & - & - & 0.0032 & 0.0099 & 0.0087 & -0.0709 & 0.0516 \\
\hline \multirow{5}{*}{$\begin{array}{l}\text { U } \\
\text { 出 } \\
\text { 己. }\end{array}$} & 0.0017 & -0.0323 & - & - & - & - & -0.0062 & 0.0264 & -0.1408 & 0.0794 \\
\hline & 0.0016 & - & -0.0098 & - & - & - & -0.0066 & 0.0214 & -0.1549 & 0.0654 \\
\hline & 0.0017 & - & - & $-0.0154^{* * *}$ & - & - & -0.0094 & 0.0014 & -0.1239 & 0.1202 \\
\hline & $0.0019^{* * *}$ & - & - & - & $-0.0425^{* *}$ & - & -0.0126 & -0.0010 & -0.0959 & 0.1667 \\
\hline & 0.0016 & - & - & - & - & -0.0299 & -0.0092 & 0.0121 & -0.1259 & 0.1077 \\
\hline \multirow{5}{*}{$\begin{array}{l}\text { 昰 } \\
\text { 号 } \\
\text { Z } \\
\text { ㄴ }\end{array}$} & 0.0004 & -0.0030 & - & - & - & - & -0.0038 & -0.0872 & $0.2336^{* * *}$ & 0.0917 \\
\hline & 0.0006 & - & -0.0130 & - & - & - & -0.0036 & -0.0760 & $0.2281^{* * *}$ & 0.0997 \\
\hline & 0.0005 & - & - & -0.0073 & - & - & -0.0051 & -0.0936 & $0.2458^{* * *}$ & 0.1084 \\
\hline & 0.0005 & - & - & - & -0.0137 & - & -0.0057 & -0.0928 & $0.2505^{* * *}$ & 0.1054 \\
\hline & 0.0006 & - & - & - & - & $-0.0343^{* * *}$ & -0.0066 & -0.0885 & $0.2620^{* *}$ & 0.1684 \\
\hline
\end{tabular}

Note: ${ }^{*},{ }^{* *}$ and ${ }^{* * *}$ means significant at $1 \%, 5 \%$ and $10 \%$ level of significance respectively.

Table 3. Estimation of the OLS regression result before the COVID-19 outbreak (continued)

\begin{tabular}{|c|c|c|c|c|c|c|c|c|c|c|}
\hline \multirow{6}{*}{ 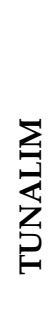 } & $\mathrm{C}$ & Bitcoin & Ethereum & Dash & Monero & Ripple & VIX & WTI & GOLD & $\mathbf{R}^{2}$ \\
\hline & 0.0010 & 0.0155 & - & - & - & - & $0.0308^{*}$ & 0.0609 & -0.1149 & 0.1839 \\
\hline & 0.0009 & - & 0.0102 & - & - & - & $0.0309^{*}$ & 0.0580 & -0.1063 & 0.1838 \\
\hline & 0.0010 & - & - & 0.0097 & - & - & $0.0328^{*}$ & 0.0745 & -0.1272 & 0.2072 \\
\hline & 0.0010 & - & - & - & 0.0162 & - & $0.0333^{*}$ & 0.0728 & -0.1310 & 0.1975 \\
\hline & 0.0011 & - & - & - & - & 0.0060 & $0.0316^{*}$ & 0.0678 & -0.1149 & 0.1813 \\
\hline \multirow{5}{*}{ 足 } & -0.0006 & $-0.0747^{* * *}$ & - & - & - & - & -0.0045 & 0.1081 & 0.0108 & 0.1051 \\
\hline & -0.0008 & - & -0.0122 & - & - & - & -0.0058 & 0.0866 & -0.0181 & 0.0429 \\
\hline & -0.0011 & - & - & -0.0024 & - & - & -0.0065 & 0.0732 & -0.0096 & 0.0399 \\
\hline & -0.0010 & - & - & - & -0.0114 & - & -0.0076 & 0.0714 & 0.0009 & 0.0442 \\
\hline & -0.0009 & - & - & - & - & -0.0334 & -0.0087 & 0.0749 & 0.0147 & 0.0794 \\
\hline \multirow{5}{*}{ 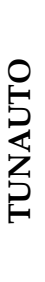 } & -0.0006 & 0.0113 & - & - & - & - & -0.0143 & -0.0029 & 0.1873 & 0.1014 \\
\hline & -0.0004 & - & -0.0069 & - & - & - & -0.0139 & 0.0086 & 0.1888 & 0.1010 \\
\hline & -0.0005 & - & - & -0.0030 & - & - & -0.0146 & $-4.63 \mathrm{E}-05$ & 0.1965 & 0.1015 \\
\hline & -0.0004 & - & - & - & -0.0196 & - & -0.0167 & -0.0040 & $0.2168^{* * *}$ & 0.1245 \\
\hline & -0.0005 & - & - & - & - & -0.0030 & -0.0143 & 0.0020 & 0.1937 & 0.0995 \\
\hline \multirow{5}{*}{ 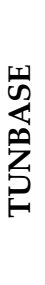 } & -0.0020 & 0.0271 & - & - & - & - & $0.0243^{* * *}$ & 0.0475 & -0.1289 & 0.0807 \\
\hline & $-0.0028^{* * *}$ & - & $0.0455^{* * *}$ & - & - & - & $0.0239^{* * *}$ & 0.0161 & -0.1045 & 0.1313 \\
\hline & -0.0019 & - & - & 0.0051 & - & - & $0.0257^{* * *}$ & 0.0632 & -0.1292 & 0.0762 \\
\hline & -0.0020 & - & - & - & 0.0189 & - & $0.0274^{* * *}$ & 0.0654 & -0.1447 & 0.0872 \\
\hline & -0.0020 & - & - & - & - & 0.0163 & $0.0262^{* * *}$ & 0.0596 & -0.1339 & 0.0817 \\
\hline \multirow{5}{*}{ 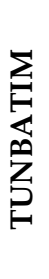 } & 0.0002 & -0.0537 & - & - & - & - & 0.0111 & 0.1204 & 0.0643 & 0.1125 \\
\hline & -0.0002 & - & 0.0033 & - & - & - & 0.0099 & 0.0934 & 0.0475 & 0.0702 \\
\hline & 0.0001 & - & - & $-0.0189^{* * *}$ & - & - & 0.0068 & 0.0836 & 0.0804 & 0.1470 \\
\hline & $-5.75 \mathrm{E}-05$ & - & - & - & -0.0100 & - & 0.0086 & 0.0935 & 0.0596 & 0.0750 \\
\hline & 8.14E-06 & - & - & - & - & -0.0261 & 0.0079 & 0.0966 & 0.0688 & 0.1006 \\
\hline \multirow{3}{*}{$\begin{array}{l}\text { n } \\
\text { Z } \\
0 \\
\text { Z }\end{array}$} & 0.0009 & 0.0154 & - & - & - & - & $0.0267^{*}$ & 0.0610 & $-0.1674^{* * *}$ & 0.1918 \\
\hline & 0.0008 & - & 0.0120 & - & - & - & $0.0267^{*}$ & 0.0564 & -0.1582 & 0.1942 \\
\hline & 0.0009 & - & - & 0.0072 & - & - & $0.0282^{*}$ & 0.0728 & $-0.1752^{* * *}$ & 0.2068 \\
\hline
\end{tabular}




\begin{tabular}{ccccccccccc}
\hline & 0.0009 & - & - & - & 0.0142 & - & $0.0289^{*}$ & 0.0722 & $-0.1809^{* * *}$ & 0.2049 \\
& 0.0010 & - & - & - & - & 0.0081 & $0.0276^{*}$ & 0.0678 & -0.1693 & 0.1908 \\
\hline & 0.0012 & -0.0185 & - & - & - & - & -0.0035 & 0.0045 & -0.1197 & 0.0422 \\
& 0.0012 & - & -0.0064 & - & - & - & -0.0037 & 0.0024 & -0.1280 & 0.0383 \\
$\mathbf{Z}$ & 0.0013 & - & - & -0.0142 & - & - & -0.0062 & -0.0134 & -0.1003 & 0.0834 \\
\hline & 0.0015 & - & - & - & $-0.0445^{* *}$ & - & -0.0099 & -0.0173 & -0.0676 & 0.1444 \\
& 0.0013 & - & - & - & - & -0.0348 & -0.0066 & -0.0036 & -0.0959 & 0.0953 \\
\hline
\end{tabular}

Note: ${ }^{*}, *$ and ${ }^{* * *}$ means significant at $1 \%, 5 \%$ and $10 \%$ level of significance respectively.

Table 4. Estimation of The OLS Regression Result During The COVID-19 Outbreak

\begin{tabular}{|c|c|c|c|c|c|c|c|c|c|c|c|c|}
\hline & $\mathrm{C}$ & Bitcoin & Ethereum & Dash & Monero & Ripple & VIX & WTI & GOLD & $\mathrm{CC}$ & CD & $\mathbf{R}^{2}$ \\
\hline \multirow{5}{*}{ 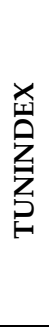 } & -0.0014 & 0.0033 & - & - & - & - & 0.0336 & -0.0079 & 0.0732 & $0.0555^{*}$ & $-0.0343^{* *}$ & 0.3813 \\
\hline & -0.0013 & - & -0.0074 & - & - & - & 0.0310 & -0.0079 & 0.0849 & $0.0550^{*}$ & $-0.0341^{* *}$ & 0.3831 \\
\hline & -0.0020 & - & - & 0.0317 & - & - & $0.0393^{* *}$ & -0.0072 & 0.0450 & $0.0566^{*}$ & $\begin{array}{c}- \\
0.0288^{* * *}\end{array}$ & 0.4195 \\
\hline & -0.0019 & - & - & - & 0.0208 & - & $0.0334^{* * *}$ & -0.0076 & 0.0529 & $0.0550^{*}$ & $\begin{array}{c}- \\
0.0314^{* * *}\end{array}$ & 0.3992 \\
\hline & -0.0016 & - & - & - & - & 0.0124 & $0.0336^{* * *}$ & -0.0075 & 0.0733 & $0.0563^{*}$ & $-0.0338^{* *}$ & 0.3852 \\
\hline \multirow{5}{*}{ 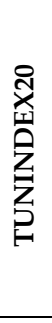 } & -0.0015 & 0.0048 & - & - & - & - & 0.0390 & -0.0099 & 0.0614 & $0.0617^{*}$ & $-0.0388^{* *}$ & 0.3685 \\
\hline & -0.0014 & - & -0.0104 & - & - & - & 0.0353 & -0.0098 & 0.0780 & $0.0610^{*}$ & $-0.0384^{* *}$ & 0.3712 \\
\hline & -0.0022 & - & - & 0.0360 & - & - & $0.0452^{* *}$ & -0.0090 & 0.0303 & $0.0629^{*}$ & $\begin{array}{c}- \\
0.0326^{* * *}\end{array}$ & 0.4062 \\
\hline & -0.0021 & - & - & - & 0.0246 & - & $0.0386^{* * *}$ & -0.0094 & 0.0382 & $0.0610^{*}$ & $\begin{array}{c}- \\
0.0353^{* * *}\end{array}$ & 0.3876 \\
\hline & -0.0018 & - & - & - & - & 0.0152 & $0.0388^{* * *}$ & -0.0093 & 0.0623 & $0.0626^{*}$ & $-0.0381^{* *}$ & 0.3729 \\
\hline \multirow{5}{*}{$\begin{array}{l}\text { 光 } \\
\text { 点 } \\
\text { 号 }\end{array}$} & -0.0021 & 0.0370 & - & - & - & - & 0.0405 & -0.0135 & 0.0520 & $0.0631^{*}$ & $\begin{array}{c}- \\
0.0362^{* * *}\end{array}$ & 0.3543 \\
\hline & -0.0018 & - & -0.0004 & - & - & - & 0.0328 & -0.0127 & 0.0875 & $0.0631^{*}$ & $\begin{array}{c}- \\
0.0380^{* * * *}\end{array}$ & 0.3391 \\
\hline & -0.0024 & - & - & 0.0299 & - & - & 0.0390 & -0.0121 & 0.0574 & $0.0641^{*}$ & -0.0326 & 0.3619 \\
\hline & -0.0024 & - & - & - & 0.0229 & - & 0.0335 & -0.0124 & 0.0612 & $0.0626^{*}$ & $0.0346^{* * *}$ & 0.3537 \\
\hline & -0.0026 & - & - & - & - & 0.0392 & 0.0349 & -0.0114 & 0.0774 & $0.0655^{*}$ & $\begin{array}{c}- \\
0.0357^{* * *}\end{array}$ & 0.3660 \\
\hline \multirow{5}{*}{ 竞 } & -0.0031 & -0.0197 & - & - & - & - & 0.0142 & -0.0064 & -0.0575 & $0.0777^{*}$ & $\begin{array}{c}- \\
0.0436^{* * *}\end{array}$ & 0.2820 \\
\hline & -0.0028 & - & -0.0637 & - & - & - & 0.0020 & -0.0070 & -0.0030 & $0.0734^{*}$ & $\begin{array}{c}- \\
0.0389^{* * * *}\end{array}$ & 0.3487 \\
\hline & $-0.0047^{* * *}$ & - & - & $0.0705^{* * *}$ & - & - & 0.0324 & -0.0054 & -0.1460 & $0.0800^{*}$ & -0.0300 & 0.3719 \\
\hline & $-0.0049^{* * *}$ & - & - & - & $0.0680^{* * *}$ & - & 0.0198 & -0.0059 & -0.1530 & $0.0759^{*}$ & -0.0324 & 0.3736 \\
\hline & $-0.0054^{* *}$ & - & - & - & - & $0.1023^{* *}$ & 0.0235 & -0.0035 & -0.1013 & $0.0838^{*}$ & $\begin{array}{c}- \\
0.0366^{* * *}\end{array}$ & 0.4138 \\
\hline \multirow{3}{*}{ 壱 } & -0.0020 & 0.0311 & - & - & - & - & 0.0356 & -0.0125 & 0.0562 & $0.0580^{*}$ & $\begin{array}{c}- \\
0.0331^{* * *}\end{array}$ & 0.3718 \\
\hline & -0.0018 & - & $-4.04 \mathrm{E}-05$ & - & - & - & 0.0292 & -0.0119 & 0.0857 & $0.0580^{*}$ & $\begin{array}{c}- \\
0.0346^{* * *}\end{array}$ & 0.3583 \\
\hline & -0.0024 & - & - & 0.0289 & - & - & 0.0351 & -0.0113 & 0.0570 & $0.0590^{*}$ & $\begin{array}{c}- \\
0.0294^{* * * *}\end{array}$ & 0.3850 \\
\hline
\end{tabular}




\begin{tabular}{|c|c|c|c|c|c|c|c|c|c|c|c|c|}
\hline & -0.0024 & - & - & - & 0.0227 & - & 0.0298 & -0.0116 & 0.0599 & $0.0575^{*}$ & $0.0312^{* * *}$ & 0.3763 \\
\hline & -0.0025 & - & - & - & - & 0.0336 & 0.0310 & -0.0108 & 0.0774 & $0.0601^{*}$ & $\begin{array}{c}- \\
0.0326^{* * *}\end{array}$ & 0.3831 \\
\hline \multirow{5}{*}{ 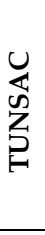 } & $-0.0034^{* *}$ & -0.0230 & - & - & - & - & 0.0046 & 0.0012 & $0.2021^{* *}$ & $0.0716^{*}$ & $-0.0451^{*}$ & 0.5525 \\
\hline & $-0.0037^{*}$ & - & 0.0054 & - & - & - & 0.0106 & 0.0007 & $0.1740^{* *}$ & $0.0720^{*}$ & $-0.0443^{*}$ & 0.5446 \\
\hline & $-0.0040^{*}$ & - & - & 0.0193 & - & - & 0.0132 & 0.0011 & $0.1611^{* *}$ & $0.0722^{*}$ & $-0.0405^{*}$ & 0.5580 \\
\hline & $-0.0041^{*}$ & - & - & - & 0.0172 & - & 0.0097 & 0.0009 & $0.1608^{* *}$ & $0.0712^{*}$ & $-0.0413^{*}$ & 0.5561 \\
\hline & $-0.0030^{* *}$ & - & - & - & - & -0.0296 & 0.0077 & -0.0002 & $0.1875^{* *}$ & $0.0698^{*}$ & $-0.0457^{*}$ & 0.5668 \\
\hline \multirow{5}{*}{$\begin{array}{l}\text { 焉 } \\
\text { Z } \\
\text { 号 }\end{array}$} & $-0.0031^{* *}$ & -0.0237 & - & - & - & - & -0.0082 & -0.0050 & 0.0941 & $0.0364^{* *}$ & $\begin{array}{c}- \\
0.0224^{* * *}\end{array}$ & 0.2834 \\
\hline & $-0.0032^{* *}$ & - & -0.0183 & - & - & - & -0.0080 & -0.0056 & 0.0927 & $0.0352^{* *}$ & $0.0202^{* * *}$ & 0.2880 \\
\hline & $-0.0031^{* *}$ & - & - & -0.0078 & - & - & -0.0050 & -0.0057 & 0.0794 & $0.0361^{* *}$ & $\begin{array}{c}- \\
0.0227^{* * *}\end{array}$ & 0.2701 \\
\hline & $-0.0034^{* *}$ & - & - & - & 0.0024 & - & -0.0033 & -0.0055 & 0.0688 & $0.0363^{* *}$ & $\begin{array}{c}- \\
0.0209^{* * *}\end{array}$ & 0.2661 \\
\hline & $-0.0028^{* *}$ & - & - & - & - & -0.0218 & -0.0045 & -0.0062 & 0.0770 & $0.0351^{* *}$ & $\begin{array}{c}- \\
0.0226^{* * *}\end{array}$ & 0.2893 \\
\hline
\end{tabular}

Note: ${ }^{*}, * *$ and ${ }^{* * *}$ means significant at $1 \%, 5 \%$ and $10 \%$ level of significance respectively.

Table 4. Estimation of The Ols Regression Result During the Covid-19 Outbreak (Continued)

\begin{tabular}{|c|c|c|c|c|c|c|c|c|c|c|c|c|}
\hline & C & Bitcoin & Ethereum & Dash & Monero & Ripple & VIX & WTI & GOLD & $\mathrm{CC}$ & CD & $\mathbf{R}^{2}$ \\
\hline \multirow{5}{*}{ 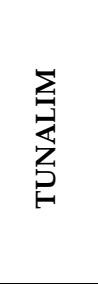 } & 0.0017 & -0.0612 & 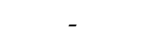 & 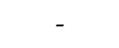 & - & 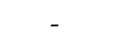 & 0.0405 & -0.0032 & 0.1926 & 0.0550 & -0.0496 & 0.2068 \\
\hline & 0.0013 & - & -0.0234 & - & - & - & 0.0470 & -0.0045 & 0.1615 & 0.0534 & -0.0452 & 0.1930 \\
\hline & 0.0003 & - & - & 0.0414 & - & - & 0.0613 & -0.0036 & 0.0935 & 0.0563 & -0.0391 & 0.2077 \\
\hline & 0.0010 & - & - & - & 0.0077 & - & 0.0531 & -0.0043 & 0.1258 & 0.0548 & -0.0454 & 0.1877 \\
\hline & 0.0023 & - & - & - & - & -0.0530 & 0.0502 & -0.0061 & 0.1475 & 0.0518 & -0.0497 & 0.2103 \\
\hline \multirow{5}{*}{ 员 } & 0.0001 & 0.0153 & - & - & - & - & 0.0081 & -0.0013 & 0.0709 & -0.0239 & 0.0296 & 0.1155 \\
\hline & $-4.92 \mathrm{E}-05$ & - & 0.0439 & - & - & - & 0.0162 & -0.0009 & 0.0350 & -0.0209 & 0.0262 & 0.1647 \\
\hline & $-5.41 \mathrm{E}-05$ & - & - & 0.0144 & - & - & 0.0079 & -0.0007 & 0.0712 & -0.0234 & 0.0314 & 0.1186 \\
\hline & -0.0003 & - & - & - & 0.0250 & - & 0.0056 & -0.0007 & 0.0572 & -0.0245 & 0.0326 & 0.1327 \\
\hline & 0.0008 & - & - & - & - & -0.0284 & 0.0036 & -0.0019 & 0.0924 & -0.0256 & 0.0271 & 0.1288 \\
\hline \multirow{5}{*}{ 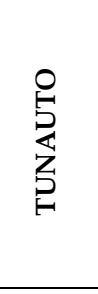 } & -0.0058 & 0.1415 & - & - & - & - & 0.0511 & $-0.0401^{* *}$ & 0.0748 & 0.0175 & 0.0452 & 0.3982 \\
\hline & -0.0046 & - & -0.0052 & - & - & - & 0.0209 & $-0.0372^{* * *}$ & 0.2149 & 0.0172 & 0.0386 & 0.3380 \\
\hline & -0.0062 & - & - & 0.0781 & - & - & 0.0379 & $-0.0357^{* * *}$ & 0.1315 & 0.0201 & 0.0524 & 0.3798 \\
\hline & -0.0063 & - & - & - & 0.0674 & - & 0.0238 & $-0.0363^{* * *}$ & 0.1327 & 0.0158 & 0.0485 & 0.3720 \\
\hline & -0.0066 & - & - & - & - & 0.0968 & 0.0272 & $-0.0341^{* * *}$ & 0.1851 & 0.0233 & 0.0441 & 0.3822 \\
\hline \multirow{5}{*}{ 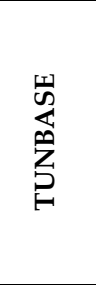 } & $-0.0069^{*}$ & 0.0088 & - & - & - & - & 0.0298 & 0.0025 & 0.0506 & $0.0572^{* * *}$ & -0.0163 & 0.2233 \\
\hline & $-0.0070^{*}$ & - & 0.0361 & - & - & - & 0.0372 & 0.0028 & 0.0175 & $0.0596^{* *}$ & -0.0189 & 0.2456 \\
\hline & $-0.0087^{*}$ & - & - & $0.0914^{* *}$ & - & - & 0.0464 & 0.0045 & -0.0314 & $0.0602^{* *}$ & -0.0002 & 0.3824 \\
\hline & $-0.0083^{*}$ & - & - & - & 0.0616 & - & 0.0295 & 0.0035 & -0.0105 & $0.0556^{* *}$ & -0.0075 & 0.3020 \\
\hline & $-0.0072^{* *}$ & - & - & - & - & 0.0199 & 0.0291 & 0.0033 & 0.0541 & $0.0584^{* *}$ & -0.0155 & 0.2279 \\
\hline \multirow{2}{*}{ 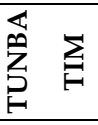 } & -0.0024 & -0.0138 & - & - & - & - & 0.0065 & -0.0021 & -0.1571 & $0.0738^{* *}$ & -0.0351 & 0.2609 \\
\hline & -0.0021 & - & -0.0536 & - & - & - & -0.0042 & -0.0026 & -0.1086 & $0.0702^{* *}$ & -0.0312 & 0.3051 \\
\hline
\end{tabular}




\begin{tabular}{|c|c|c|c|c|c|c|c|c|c|c|c|c|}
\hline & -0.0037 & - & - & 0.0604 & - & - & 0.0215 & -0.0012 & -0.2300 & $0.0758^{*}$ & -0.0235 & 0.3226 \\
\hline & -0.0040 & - & - & - & 0.0591 & - & 0.0107 & -0.0016 & -0.2369 & $0.0723^{* *}$ & -0.0255 & 0.3254 \\
\hline & $-0.0045^{* * *}$ & - & - & - & - & $0.0955^{* * *}$ & 0.0142 & 0.0006 & -0.1935 & $0.0795^{*}$ & -0.0288 & 0.3676 \\
\hline \multirow{5}{*}{ 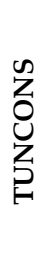 } & 0.0011 & -0.0495 & - & - & - & - & 0.0391 & -0.0007 & 0.1072 & 0.0458 & -0.0370 & 0.1939 \\
\hline & 0.0008 & - & -0.0168 & - & - & - & 0.0449 & -0.0018 & 0.0796 & 0.0446 & -0.0336 & 0.1802 \\
\hline & 5.46E-05 & - & - & 0.0310 & - & - & 0.0554 & -0.0011 & 0.0296 & 0.0468 & -0.0290 & 0.1921 \\
\hline & 0.0005 & - & - & - & 0.0070 & - & 0.0494 & -0.0016 & 0.0524 & 0.0456 & -0.0335 & 0.1767 \\
\hline & 0.0016 & - & - & - & - & -0.0429 & 0.0470 & -0.0031 & 0.0708 & 0.0432 & -0.0371 & 0.1973 \\
\hline \multirow{5}{*}{ 号 } & $-0.0035^{* *}$ & -0.0188 & - & - & - & - & 0.0050 & 0.0026 & $0.1950^{* *}$ & $0.0721^{*}$ & $-0.0428^{*}$ & 0.5294 \\
\hline & $-0.0037^{* *}$ & - & 0.0083 & - & - & - & 0.0109 & 0.0023 & $0.1675^{* * *}$ & $0.0726^{*}$ & $-0.0424^{*}$ & 0.5261 \\
\hline & $-0.0042^{*}$ & - & - & 0.0253 & - & - & 0.0139 & 0.0027 & $0.1521^{* * *}$ & $0.0729^{*}$ & $-0.0374^{* *}$ & 0.5468 \\
\hline & $-0.0043^{*}$ & - & - & - & 0.0250 & - & 0.0094 & 0.0026 & $0.1489^{* * *}$ & $0.0714^{*}$ & $-0.0382^{*}$ & 0.5484 \\
\hline & $-0.0032^{* *}$ & - & - & - & - & -0.0235 & 0.0076 & 0.0015 & $0.1829^{* *}$ & $0.0706^{*}$ & $-0.0433^{*}$ & 0.5375 \\
\hline
\end{tabular}

Note: ${ }^{*}{ }^{* *}$ and ${ }^{* * *}$ means significant at $1 \%, 5 \%$ and $10 \%$ level of significance respectively.

Based on the categorization of Baur and Lucey (2010), the results of the OLS regression analyses show that there is a negative significant relationship between Bitcoin and the Tunisian stock market indices TUNASS before the Coronavirus outbreak suggesting the use of Bitcoin as a hedge in such portfolio; whereas, there is no significant relationship between Bitcoin and the rest of the Tunisian stock market indices neither before nor during the COVID-19 outbreak; which means that Bitcoin cannot act as a haven during the pandemic. This result is consistent with Ji et al. (2020) who indicated that the role of Bitcoin, as a potential safe-haven asset for equity indices, becomes less effective during the pandemic period, and Conlon et al. (2020) who find that Bitcoin and Ethereum cannot act as a safe haven for international equity markets during such period.

From Table 3, results show that before the COVID-19 outbreak there is a positive significant relationship between Ethereum and TUNBASE suggesting the use of Ethereum as a diversifier. Also, there is a negative significant relationship between Dash and the two indices TUNSAC and TUNBATIM, between Monero, TUNSAC, and TUNDIS, and between Ripple and TUNSEFI, which indicates that these three cryptocurrencies act as hedges. Table 3 also shows that there is a low positive significant relationship between the VIX index and five of the Tunisian stock market indices which are TUNINDEX, TUNINDEX20, TUNALIM, TUNBASE, and TUNCONS. There is also a positive significant relationship between Oil and TUNIND, which indicates the diversification properties of the VIX and WTI indexes.

Before the COVID-19 outbreak, gold has a negative significant relationship with TUNINDEX, TUNINDEX20, and TUNIND, which indicates that it acts as a hedge for these indices. It also has a positive significant relationship with TUNSEFI, indicating that it acts as a diversifier in this case. Moreover, gold can act as a diversifier for the TUNAUTO indices but with the presence of Monero and as a hedge for TUNCONS but with the presence of Bitcoin, Dash, and Monero.

From Table 4, results show that during the 2020 global pandemic there is a low significant positive relationship between Dash, TUNIND, and TUNBASE, between Monero and TUNIND, and between Ripple, TUNIND, and TUNBATIM, which indicates the diversification properties of these three cryptocurrencies during the Coronavirus pandemic.

Moreover, the results show a low significant positive relationship between the VIX index, TUNINDEX, and TUNINDEX20 but with the presence of Dash, Monero, and Ripple, which suggest that the VIX index act as a diversifier for these two Tunisian stock indices. At the same time, the Oil index can be considered as a haven asset for the TUNAUTO indices.

During the COVID-19 outbreak, the results of the OLS regression analyses show that the yellow metal has a significant positive relationship with TUNSAC and TUNDIS, which implies that it acts as 
a diversifier for the Tunisian stock market indices during the COVID-19 pandemic. This result is inconsistent with Baur and Lucey (2010) who suggested that gold acts as a haven asset in extreme stock market conditions and with Ji et al. (2020) who find out that gold can be used as a safe-haven asset during the COVID-19 outbreak given its irreplaceable role in conserving the value of an investment.

Finally, inconsistency with Al- Awadhi et al. (2020), Baig et al. (2020), and Badar Nadeem Ashraf (2020) results in Table 4 indicate that the growth rate of the COVID-19 confirmed cases and deaths harms the Tunisian stock market indices. This is due to the strong uncertainties and risks perceived by investors regarding the economic and social impacts of the COVID-19 spread in the country and the unprecedented measures (containment measures, borders closure, ...) taken by the Tunisian government.

\section{Conclusions}

With the appearance and spread of the COVID-19 pandemic across the world, the uncertainty for countries has increased. In this paper, we focus on the determinants of the Tunisian stock market returns during the Coronavirus outbreak. We find that the series returns are more volatile during the COVID-19 outbreak than during the period before the COVID-19. The cryptocurrency market has shown relatively calm with lower volatility before the pandemic. However, after the appearance of COVID-19, these digital assets became more volatile. Bitcoin is considered the less volatile among all, while Monero and Ripple are the most volatile. Gold is usually considered an effective safe haven during extreme market conditions; however, during the Coronavirus outbreak, it has shown high volatility, which means that gold is not playing the role of a safe haven that it has always performed before. Also, the Tunisian stock market indices became more volatile since the appearance of the pandemic in the country.

Using the OLS regression, results reveal that Bitcoin act as a hedge and Ethereum as a diversifier for Tunisia's stock market before the COVID-19 outbreak; however, Bitcoin and Ethereum cannot generate benefits from portfolio diversification, safe haven, and hedging strategies for Tunisia's financial investors during the COVID-19. Also, Dash, Monero, and ripple act as hedges before the COVID-19 outbreak and as diversifiers during this pandemic. Also, results indicate that gold is neither hedge nor a safe haven during the COVID-19 pandemic but it acts as a hedge for TUNINDEX, TUNINDEX20, and TUNIND before the COVID-19 outbreak. It also shows that the expected volatility of the US stock market has an impact on the Tunisian stock market and the Oil index can be considered as a safe haven asset. Finally, results show that the growth rate of the confirmed COVID-19 cases and deaths harms Tunisia's stock market returns.

Author Contributions: This is the first paper that examines the impact of the COVID-19 pandemic on the Tunisian stock market and it is also the first that studies the introduction of cryptocurrencies in Tunisia and treats their safe haven properties.

Funding: This research received no external funding.

Conflicts of Interest: The authors certify that they have NO affiliations with or involvement in any organization or entity with any financial interest, or non-financial interest in the subject matter or materials discussed in this manuscript.

\section{References}

Ahmar, A.S., \& Del Val, E.B. (2020). SutteARIMA: Short-term forecasting method, a case: Covid-19 and the stock market in Spain. Science of the Total Environment, 729 (8), 138883. https://doi.org/10.1016/j.scitotenv.2020.138883

Al-Awadhi, A.M., Al-Saifi, K., Al-Awadhi, A., \& Alhamadi, S. (2020). Death and contagious infectious diseases: Impact of the COVID-19 virus on stock market returns. Journal of behavioral and experimental science, 27 (9), 100326. https://doi.org/10.1016/j.jbef.2020.100326 
Aysan, A.F., Demir, E., Gozgor, G., \& Lau, C.K.M. (2019). Effects of the geopolitical risks on Bitcoin returns and volatility. Research in International Business and Finance, 47 (1), 511-518. https://doi.org/10.1016/j.ribaf.2018.09.011

Bader, N.A. (2020). Stock markets' reaction to COVID-19: Cases or fatalities? Research in International Business and Finance, 54(12), 101249. https://doi.org/10.1016/j.ribaf.2020.101249

Baig, A.S., Butt, H.A., Haroon, O., \& Rizvi, S.A.R. (2020). Deaths, panic, lockdowns, and US equity markets: the case of COVID-19 pandemic. Finance Research Letters, xx (7), 101701. https://doi.org/10.1016/j.frl.2020.101701

Baur, D.G., \& Lucey, B.M. (2010). Is gold a hedge or a safe haven? An analysis of stocks, bonds and gold. The Financial. Review, 45 (2), 217-229. https://dx.doi.org/10.2139/ssrn.952289

Baur, D. G., \& McDermott, T. K. (2010). Is gold a safe haven? International evidence. Journal of Banking E Finance, 34 (8), 1886-1898. https://doi.org/10.1016/j.jbankfin.2009.12.008

Baur, D. G., \& McDermott, T. K. (2016). Why is gold a safe haven? Journal of Behavioral

and Experimental Finance, 10 (6), 63-71. https://doi.org/10.1016/j.jbef.2016.03.002

Baur, D. G., Hong, K., \& Lee, A. D. (2018). Bitcoin: Medium of exchange or speculative

assets? Journal of International Financial Markets, Institutions and Money, 54 (5), 177-189. https://doi.org/10.1016/j.intfin.2017.12.004

Beckmann, J., Berger, T., \& Czudaj, R. (2015). Does gold act as a hedge or a safe haven for

stocks? A smooth transition approach. Economic Modelling, $48 \quad$ (8), 16-24. https://doi.org/10.1016/j.econmod.2014.10.044

Bouri, E., Molnár, P., Azzi, G., Roubaud, D., \& Hagfors, L.I. (2017). On the hedge and safe haven properties of Bitcoin: is it really more than a diversifier? Finance Research Letters, 20 (2), 192-198. https://doi.org/10.1016/j.frl.2016.09.025

Bouri, E., Shahzad, S., Roubaud, D., Kristoufek, L., \& Lucey, B. (2020). Bitcoin, gold, and commodities as safe havens for stocks: New insight through wavelet analysis. The Quarterly Review of Economics and Finance, 77 (8), 156-164. https://doi.org/10.1016/j.qref.2020.03.004

Bouri, E., Lucey, B., \& Roubaud, D. (2019). Cryptocurrencies and the downside risk in equity investments. Finance Research Letters, 33 (3), 101211. https://doi.org/10.1016/j.frl.2019.06.009

Cheema, M.A., Faff, R.W., \& Szulczuk, K. (2020). The 2008 Global Financial Crisis and COVID-19 Pandemic: How Safe is the Safe Haven Assets? https://dx.doi.org/10.2139/ssrn.3590015

Conlon, T., \& McGee, R. (2020). Safe haven or risky hazard? Bitcoin during the COVID-19 bear market. Finance Research Letters, 35 (7), 101607. https://doi.org/10.1016/j.frl.2020.101607

Corbet, S., Meegan, A., Larkin, C., Lucey, B., \& Yarovaya, L. (2018). Exploring the dynamic relationships between cryptocurrencies and other financial assets. Economics Letters, 165 (4), 28-34. https://doi.org/10.1016/j.econlet.2018.01.004

Corbet, S., Larkin, C., \& Lucey, B. (2020). The contagion effects of the COVID-19 pandemic: Evidence from gold and cryptocurrencies. Finance Research Letters, 35 (7), 101554. https://doi.org/10.1016/j.frl.2020.101554

Corbet, S., (Greg) Hou, Y., Hu, Y., Larkin, C., \& Oxley, L. (2020a). Any port in a storm: Cryptocurrency safe-havens during the COVID-19 pandemic. Economics Letters, $194 \quad$ (9), 109377. https://doi.org/10.1016/j.econlet.2020.109377

Feng, W., Wang, Y., \& Zhang, Z. (2018). Can cryptocurrencies be a safe haven: a tail risk perspective analysis. Applied Economics, 50 (4), 4745-4762. https://doi.org/10.1080/00036846.2018.1466993

Fernandes, N. (2020). Economic effects of coronavirus outbreak (COVID-19) on the world economy. https://dx.doi.org/10.2139/ssrn.3557504

Gates, B. (2020). Responding to Covid-19-A once-in-a-century pandemic? New England Journal of Medicine, 382 (4), 1677-1679. DOI: 10.1056/NEJMp2003762

Gil-Alana, L., Abakah, E., \& Rojo, M. (2020). Cryptocurrencies and stock market indices. are they related? Research in International Business and Finance, 51(1), 101063. https://doi.org/10.1016/j.ribaf.2019.101063

Goodwell, J. W. (2020). COVID-19 and finance: Agendas for future research. Finance Research Letters, 35 (7), 101512. https://doi.org/10.1016/j.frl.2020.101512

Gorton, G., Lewellen, S., \& Metrick, A. (2012). The safe-asset share. American Economic Review. 102 (3), $101-106$. DOI: 10.1257/aer.102.3.101 
Guesmi, K., Saadi, S., Abid, I., \& Ftiti, Z. (2019). Portfolio diversification with virtual currency: evidence from bitcoin. International Review of Financial Analysis, 63 (5), 431-437. https://doi.org/10.1016/j.irfa.2018.03.004

Han, H., Linton, O., Oka, T., \& Whang, Y. J. (2016). The cross-quantilogram: Measuring quantile dependence and testing directional predictability between time series. Journal of Econometrics, 193 (7), 251-270. https://doi.org/10.1016/j.jeconom.2016.03.001

Hood, M., \& Malik, F. (2013). Is gold the best hedge and a safe haven under changing stock market volatility? Review of Financial Economics. 22 (2), 47-52. https://doi.org/10.1016/j.rfe.2013.03.001

Ji, Q., Zhang, D., \& Zhao, Y. (2020). Searching for safe-haven assets during the COVID-19 pandemic. International Review of Financial Analysis. 71 (10), 101526. https://doi.org/10.1016/j.irfa.2020.101526

Klein, T., Thu, H. P., \& Walther, T. (2018). Bitcoin is not the new gold-A comparison of volatility, correlation, and portfolio performance. International Review of Financial Analysis, 59 (10), 105-116. https://doi.org/10.1016/j.irfa.2018.07.010

Kliber, A., Marszałek, P., Musiałkowska, I., \& Świerczyńska, K. (2019). Bitcoin: safe haven, hedge, or diversifier? Perception of bitcoin in the context of a country's economic situation - a stochastic volatility approach. Physica A: Statistical Mechanics and its Applications, 524 (6), $246-257$. https://doi.org/10.1016/j.physa.2019.04.145

Liu, W. (2019). Portfolio diversification across cryptocurrencies. Finance Research Letters, 29 (6), 200-205. https://doi.org/10.1016/j.frl.2018.07.010

Lucey, B. M., \& Li, S. (2015). What precious metals act as safe havens, and when? Some US evidence. Applied Economics Letters, 22(1), 35-45. https://doi.org/10.1080/13504851.2014.920471

Nakamoto, S. (2008). Bitcoin: A peer-to-peer electronic cash system.

Reboredo, J.C. (2013). Is gold a safe-haven or a hedge for the US dollar? Implications for risk management. Journal of Banking \& Finance, 37 (8), 2665-2676. https://doi.org/10.1016/j.jbankfin.2013.03.020

Shahzad, S.J.H., Bouri, E., Roubaud, D., Kristoufek, L., \& Lucey, B. (2019). Is Bitcoin a better safe-haven investment than gold and commodities? International Review of Financial Analysis, 63 (5), 322-330. https://doi.org/10.1016/j.irfa.2019.01.002

Smales, L.A. (2019). Bitcoin as a safe haven: Is it even worth considering? Finance Research Letters, 30 (9), $385-393$. https://doi.org/10.1016/j.frl.2018.11.002

Smith, R.D. (2006). Responding to global infectious disease outbreaks: Lessons from SARS on the role of risk perception, communication, and management. Social Science $\mathcal{E}$ Medicine, 63 (12), 3113-3123. https://doi.org/10.1016/j.socscimed.2006.08.004

Tiwari, A., Raheem, I., Kang, S. (2019). Time-varying dynamic conditional correlation between stock and cryptocurrency markets using the copula-ADCC-EGARCH model. Physica A: Statistical Mechanics and its Applications, 535 (12), 122295. https://doi.org/10.1016/j.physa.2019.122295

Urquhart, A., and Zhang, H. (2019). Is Bitcoin a hedge or safe haven for currencies? An intraday analysis. International Review of Financial Analysis, 63 (4), 49-57. https://doi.org/10.1016/j.irfa.2019.02.009

Zhang, D., Hu, M., \& Ji, Q. (2020). Financial markets under the global pandemic of COVID-19. Finance Research Letters, 36 (10), 101528. https://doi.org/10.1016/j.frl.2020.101528

(C) 2020 by the authors. This article is an open-access article distributed under the terms and conditions of the Creative Commons Attribution (CC BY) license (http://creativecommons.org/licenses/by/4.0/). 